\title{
Bringing Radiotracing to Titanium-Based Antineoplastics: Solid Phase Radiosynthesis, PET and ex Vivo Evaluation of Antitumor Agent [45Ti](salan)Ti(dipic)
}

Severin, Gregory; Nielsen, Carsten H.; Jensen, Andreas Tue Ingemann; Fonslet, Jesper; Kjær, Andreas; Zhuravlev, Fedor

Published in:

Journal of Medicinal Chemistry

Link to article, DOI:

10.1021/acs.jmedchem.5b01167

Publication date:

2015

Document Version

Peer reviewed version

Link back to DTU Orbit

Citation (APA):

Severin, G., Nielsen, C. H., Jensen, A. T. I., Fonslet, J., Kjær, A., \& Zhuravlev, F. (2015). Bringing Radiotracing to 5 Titanium-Based Antineoplastics: Solid Phase Radiosynthesis, PET and ex Vivo Evaluation of Antitumor Agent

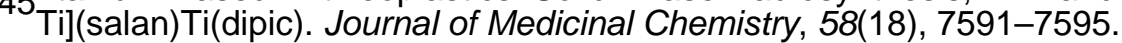

https://doi.org/10.1021/acs.jmedchem.5b01167

\section{General rights}

Copyright and moral rights for the publications made accessible in the public portal are retained by the authors and/or other copyright owners and it is a condition of accessing publications that users recognise and abide by the legal requirements associated with these rights.

- Users may download and print one copy of any publication from the public portal for the purpose of private study or research.

- You may not further distribute the material or use it for any profit-making activity or commercial gain

- You may freely distribute the URL identifying the publication in the public portal 


\title{
Bringing radiotracing to titanium-based antineoplastics: solid phase radiosynthesis, PET and ex-vivo evaluation of anti- tumor agent $\left[{ }^{45} \mathrm{Ti}\right]$ (salan) $\mathrm{Ti}($ dipic).
}

\author{
Gregory W. Severin ${ }^{\dagger}$, Carsten H. Nielsen ${ }^{\S, \ddagger}$, Andreas I. Jensen ${ }^{\dagger}$, Jesper Fonslet ${ }^{\dagger}$, Andreas Kjær ${ }^{\S}$ \\ and Fedor Zhuravlev ${ }^{\dagger *}$. \\ ${ }^{\dagger}$ Hevesy Laboratory, Center for Nuclear Technologies at the Technical University of Denmark, Frederiksborgvej \\ 399, 4000 Roskilde, Denmark. \\ ${ }^{\S}$ Department of Clinical Physiology, Nuclear Medicine \& PET and Cluster for Molecular Imaging, Rigshospitalet and \\ University of Copenhagen, Blegdamsvej 3, 2200 Copenhagen, Denmark. \\ ${ }^{\ddagger}$ Minerva Imaging, Ole Maaløes Vej 3, 2200 Copenhagen, Denmark \\ *Correspondence email: fezh@dtu.dk
}

KEYWORDS titanium, titanium-45, ${ }^{45} \mathrm{Ti}$, Positron Emission Tomography, metallodrugs, salan

\begin{abstract}
We present a novel solid-phase based ${ }^{45} \mathrm{Ti}$ radiolabeling methodology and the implementation of ${ }^{45} \mathrm{Ti}$-PET in titanium-based antineoplastics using the showcase compound $\left.{ }^{45} \mathrm{Ti}\right](\mathrm{salan}) \mathrm{Ti}(\mathrm{dipic})$. This development is intended to allow elucidation of the biodistribution and pharmacokinetics of promising new Ti-based therapeutics.
\end{abstract}

\section{- INTRODUCTION}

The success of Pt-based anticancer drugs has spurred intense research activity directed towards development of new metal-based antitumor agents ${ }^{1-3}$. Among few others, Ti has emerged as a promising antineoplastic metal ${ }^{4}$. Following encouraging preclinical results the first generation of anticancer drugs, $\mathrm{Cp}_{2} \mathrm{TiCl}_{2}$ and budotitane entered clinical trials but eventually failed to translate due to poor solubility and high hydrolytic instability of titanium ${ }^{4,5}$. However, recent advances in titanium-stabilizing ligands have led to a new class of cytotoxic Ti-based antineoplastics $^{5}$. Prominently, introduction of the ligand salan, a diamine bisphenalato compound, conferred excellent hydrolytic stability to $\mathrm{Ti}(\mathrm{IV})$ alkoxide complexes, as presented by Tshuva and co-workers (Chart 1, 1 $)^{6-13}$. Many of these compounds also demonstrated micro- and submicromolar antiproliferative activity against HT29 and OVCAR-1 cancer cell lines in vitro. In line with developed structure-activity relationships ${ }^{14}$, by substituting the terminal alkoxide ligands (OR in Chart 1, 1) with dipicolinic acid, Immel et al. obtained a hydrolytically and chromatographically stable complex, (salan)Ti(dipic) (Chart 1, 2) ${ }^{14}$. 2 exhibited cytotoxicity against HeLa $\mathrm{S}_{3}$ and Hep G2 cell lines: a finding that prompted in vivo therapeutic tests in tumor-bearing mice ${ }^{14}$.

Generally, the transition from in vitro cell cultures to in vivo application raises important considerations about the biological fate of a potential pharmaceutical. Positron emission tomography (PET) addresses these concerns by non-invasively determining the concentrations of radiolabeled compounds as they distribute in vivo ${ }^{16}$. The similar technique of single photon computed tomography (SPECT) has recently been employed to clinically determine the distribution of $\left[{ }^{195 m} \mathrm{Pt}\right]$ cisplatin in an effort to relate the pharmacokinetics to treatment efficacy ${ }^{17}$. Turning to Ti-based antineoplastics, implementation of PET and radiotracing early in preclinical development could aid in determining the mechanism of action, and evaluate dosing and drug formulation. In the present case PET is made possible by the titanium isotope ${ }^{45} \mathrm{Ti}$.

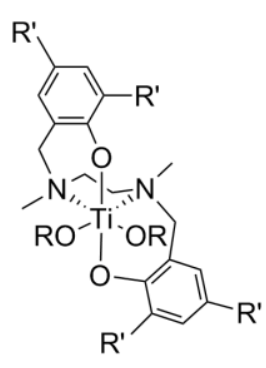

1

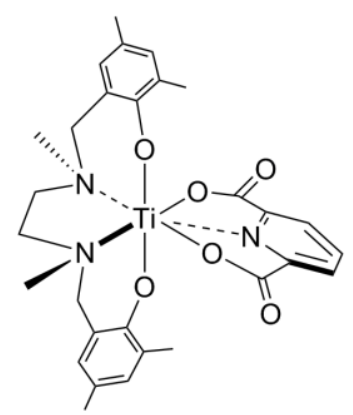

2
Chart 1, Ti-based antineoplastic agents $\mathbf{R}=$ alkyl, aryl, R'=alkyl, halogen. 


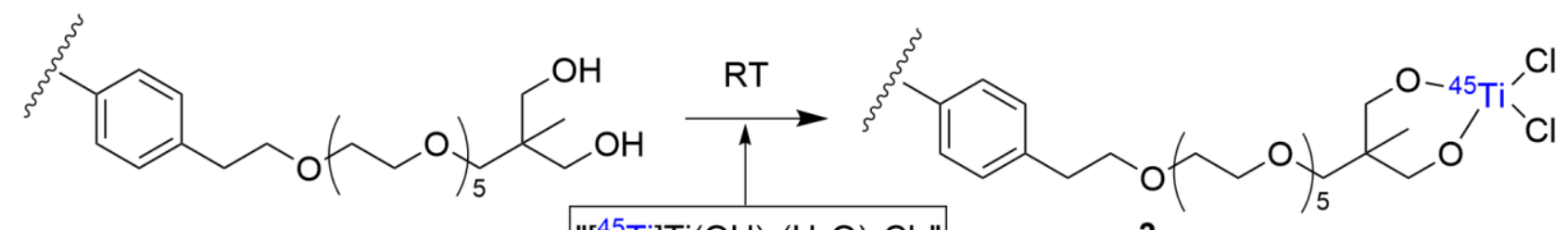

HypoGel 200

$\left[{ }^{45} \mathrm{Ti}\right] \mathrm{Ti}(\mathrm{OH})_{2}\left(\mathrm{H}_{2} \mathrm{O}\right)_{4} \mathrm{Cl}_{2} "$

3

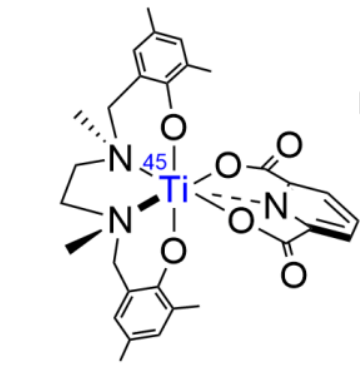

$\left[{ }^{45} \mathrm{Ti}\right]$ (salan)Ti(dipic)

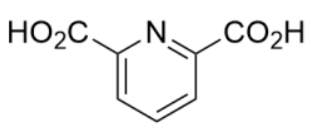

Py

$100^{\circ} \mathrm{C}, 15 \mathrm{~min}$

$\left[{ }^{45} \mathrm{Ti}\right] 2$

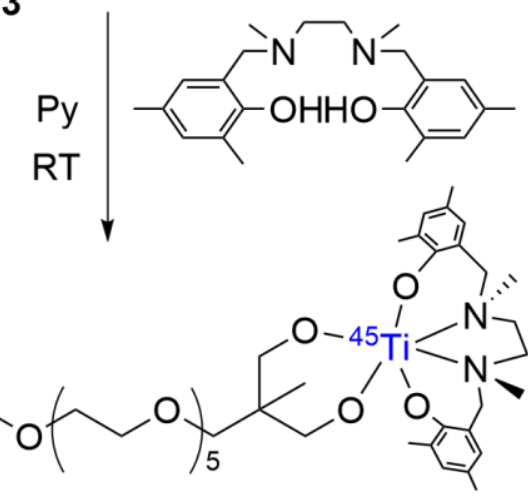

4

\section{Scheme 1, Radiosynthesis of $\left[{ }^{45} \mathrm{Ti}\right]\left(\right.$ salan)Ti(dipic), $\left[{ }^{45} \mathrm{Ti}\right] 2$ on Hypogel 200 resin}

Amongst positron emitting radionuclides, ${ }^{45} \mathrm{Ti}$ is highly desirable for biomedical application due to its decay characteristics: an $85 \%$ positron branch, low beta endpoint energy (1.04 MeV), 3.1 h half-life, and negligible secondary radiation ${ }^{18}$. Further, it is produced in high-yield by transmutation of naturally monoisotopic scandium via low energy proton irradiation ${ }^{19}$. Despite the promising physical characteristics, ${ }^{45} \mathrm{Ti}$ radiochemistry is currently underdeveloped due to the hydrolytic instability of $\mathrm{Ti}(\mathrm{IV})$ in aqueous environments. While the titanium citrate complex is mildly stable ${ }^{20}$, previous radiochemical application of [ $\left.{ }^{45} \mathrm{Ti}\right]$ titanium citrate by Ishiwata et $\mathrm{al}^{21}$ and Vãvere et $\mathrm{al}^{22,23}$ ended with partially hydrolyzed titanylbased complexes: precluding its use as an organometallic precursor.

In order to bring the utility of ${ }^{45} \mathrm{Ti}$ into the new salanbased antineoplastic complexes we sought a method of ${ }^{45} \mathrm{Ti}$ recovery and chemical-activation on solid-phase. We hypothesized that a diol-functionalized resin would trap ${ }^{45} \mathrm{Ti}$ as a titanium diolate forming a resin-bound substrate structurally similar to $\mathrm{Ti}(\mathrm{i}-\mathrm{PrO})_{4}$ used for the synthesis of 1 and 2 (Scheme 1 ).

In this preliminary report we present a novel solid phasebased ${ }^{45} \mathrm{Ti}$ recovery and radiolabeling methodology which potentially allows access to the wealth of organotitanium chemistry. This methodology is showcased by automated solid-phase radiosynthesis of antineoplastic [ $\left.{ }^{45} \mathrm{Ti}\right]$ (salan)Ti(dipic), $\left[{ }^{45} \mathrm{Ti}\right] \mathbf{2}$, and its PET imaging and ex vivo evaluation in HT-29 colorectal tumor-bearing mice.

\section{- RESULTS AND DISCUSSION}

Overall, the solid phase protocol allowed for efficient extraction of ${ }^{45} \mathrm{Ti}$ from the Sc matrix and a flexible introduction of multiple ligands, the excess of which could be removed by simple cartridge purification. ${ }^{45} \mathrm{Ti}$, produced by the ${ }^{45} \mathrm{Sc}(\mathrm{p}, \mathrm{n})^{45} \mathrm{Ti}$ nuclear reaction in a cyclotron, was efficiently isolated from bulk scandium and hydrochloric acid solution on a column packed with HypoGel 200, a PEG-functionalized polystyrene-based symmetrical 1,3 diol, with $93 \pm 3 \%$ recovery $(n=6)$. Although the exact form of $\mathrm{Ti}(\mathrm{IV})$ in conc. $\mathrm{HCl}$ is not known, a line of experimental evidence suggest $\left[\mathrm{Ti}(\mathrm{OH})_{2}\left(\mathrm{H}_{2} \mathrm{O}\right)_{4}\right] \mathrm{Cl}_{2}$ as a likely species $^{24}$ (Scheme 1). Only traces of scandium were retained on the column. This result agreed well with the measured distribution constants of Ti and Sc, where $\mathrm{K}_{\mathrm{Ti}}=$ $91.4 \pm 10.5 \mathrm{~mL} / \mathrm{mg}$ and $K_{\mathrm{Sc}}=6.8 \pm 1.4 \mathrm{~mL} / \mathrm{mg}$. With ${ }^{45} \mathrm{Ti}$ trapped on solid phase presumably as titanium diolate (Scheme 1, 3), the stage was set for introduction of salan and dipic.

Preliminary experiments with non-radiolabeled materials revealed that salan and $\mathbf{2}$ had very similar retention on silica in our TLC system. To ensure chemical purity of the desired $\left[{ }^{45} \mathrm{Ti}\right]_{2}$ the introduction of salan and dipic were performed sequentially. An on-column reaction of resin-bound ${ }^{45} \mathrm{Ti}$ with salan occurred by a slow passage of the ligand through the resin (Scheme 1, 4). Unreacted salan was removed from the column by washing the resin with pyridine. These two steps combined were accompanied by a $2-7 \%(\mathrm{n}=3)$ loss of radioactivity from the column. In the final step dipic was introduced. A control experiment performed under homogeneous conditions with non-radioactive (salan) $\mathrm{Ti}(\mathrm{i}-\mathrm{PrO})_{2}$ and dipic showed that elevated temperature was required for formation of 
2. Accordingly, dipic was introduced by recirculation of dipic in pyridine solution through the column at $100{ }^{\circ} \mathrm{C}$. $25-35 \%(n=3)$ of the ${ }^{45} \mathrm{Ti}$ was removed from the column at this step, of which $47-60 \%(n=3)$ was present as $\left[{ }^{45} \mathrm{Ti}\right] \mathbf{2}$, and the rest as unidentified $\left[{ }^{45} \mathrm{Ti}\right] \mathrm{Ti}$-containing species having high affinity for silica. The resulting [ $\left.{ }^{45} \mathrm{Ti}\right] \mathbf{2}$ was purified by passing the solution through a silica cartridge, dilution with $\mathrm{NH}_{4} \mathrm{Cl}_{(\mathrm{aq})}$ and trapping [ $\left.{ }^{45} \mathrm{Ti}\right] \mathbf{2}$ on the Sep-Pak $\mathrm{C}_{1} 8$ cartridge. The product was released from the C18 cartridge by elution with ethanol with an overall $15 \pm$ $4 \%(n=5)$ decay-corrected radiochemical yield (RCY) and $98 \%$ radiochemical purity $(\mathrm{RCP})$ as evidenced by the HPLC/radio-HPLC and TLC/radio-TLC analysis (see ESI). ICP-OES analysis showed the specific activity of $\left[{ }^{45} \mathrm{Ti}\right] \mathbf{2}$ to be $10.7 \mathrm{MBq} / \mathrm{nmol}$ at the end of purification, and containing only $1.4 \mathrm{pmol}$ of scandium per MBq.

In order to investigate the in vivo behavior of $\mathbf{2}$, three different formulations of $\left[{ }^{45} \mathrm{Ti}\right]_{2}$ were created. In order to study the dynamic biodistribution and blood-clearance kinetics of 2, a formulation suitable for intravenous injection was made without carrier in saline containing $1 \%$ (w/v) Tween 20 and $10 \mathrm{mM}$ HEPES buffer ( $\mathrm{pH} 7.4$ ): 'nocarrier-added intravenous' (ncaiv). To match the reported conditions of Immel et al.: i.e. an intraperitoneal injection of [ $\left.{ }^{45} \mathrm{Ti}\right] \mathbf{2}$ with $112 \mu \mathrm{g}$ non-radiolabeled 2 , dissolved in DMSO, the second formulation was prepared. In our hands, this concentration of $\mathbf{2}$ was only achievable in neat DMSO. This formulation is referred to as 'carrier-added intraperitoneal' (caip). In order to identify any saturation behavior of $\mathbf{2}$, a third formulation was made in DMSO without added carrier, herein: 'no-carrier-added intraperitoneal' (ncaip).

\section{Dynamic PET, ncaiv}

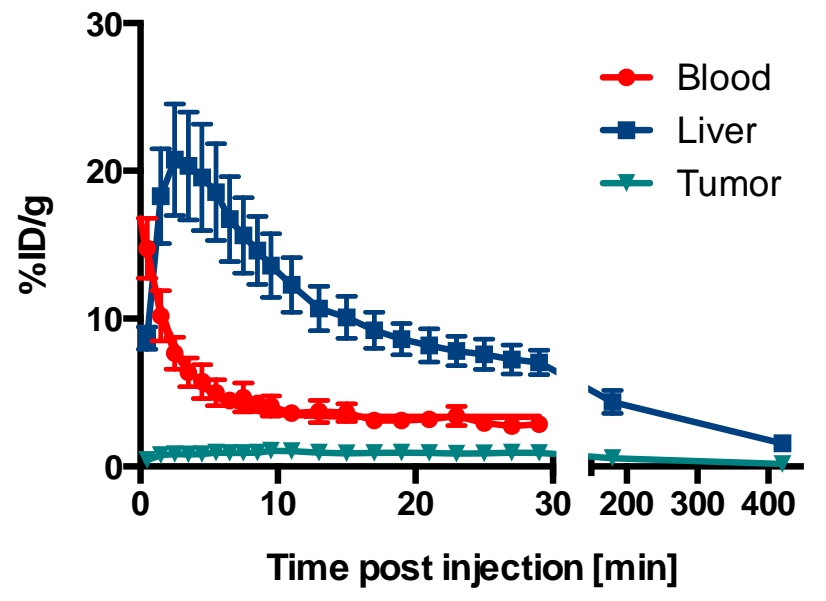

Figure 1, Dynamic PET time-activity-curve of the blood, liver and tumor ROI following ncaiv injection of $\left[{ }^{45} \mathrm{Ti}\right] \mathbf{2}$. The blood clearance was very rapid and followed a mono-exponential decay between 1 and 30 min post-injection with a half-time of $1.7 \mathrm{~min}$, and baseline of $3.3 \% \mathrm{ID} / \mathrm{g}$. Points represent mean and error bars SEM $(n=3)$.

Imaging and biodistribution studies were carried out with NMRI nude mice bearing dual-flank HT-29 colorectal adenocarcinoma xenograft tumors. For the ncaiv injection, dynamic PET data were obtained for 30 minutes followed by static scans 3 and 7 hours after injection. The blood clearance rate was determined by quantifying a region of interest (ROI) over the heart and is illustrated in Figure 1, where a rapid $1.7 \mathrm{~min}$ half-time was observed between 1 and 30 minutes post injection. This demonstrates that the circulation time of $\mathbf{2}$ is extremely short. The dynamic biodistribution is further demonstrated in a series of PET images, each corresponding to specific time point after ncaiv injection in Figure $2(n=3)$. One can see that from the bloodstream the radioactivity has relocated to the liver, then to the gall bladder, and then to the intestines, showing distinctive hepatobiliary excretion pattern, with almost no renal clearance (see also the video, ESI). Expressed as the percentage of the injected dose per gram tissue $(\% \mathrm{ID} / \mathrm{g})$, the tumor accumulation never exceeded $1 \% \mathrm{ID} / \mathrm{g}$. To ascertain the degree of metabolic transformation $\left[{ }^{45} \mathrm{Ti}\right] \mathbf{2}$ underwent while still in the bloodstream a blood sample was taken 10 minutes post iv injection. The sample was mixed with ethanol, centrifuged and the supernatant was analyzed by TLC/radio-TLC. All soluble radioactivity co-eluted with $\mathbf{2}$, indicating that it was present as chemically unmodified [ $\left.{ }^{45} \mathrm{Ti}\right] \mathbf{2}$. Overall, $61 \%$ of the radioactivity was present in the supernatant, and the rest was tightly bound to the pellet. 


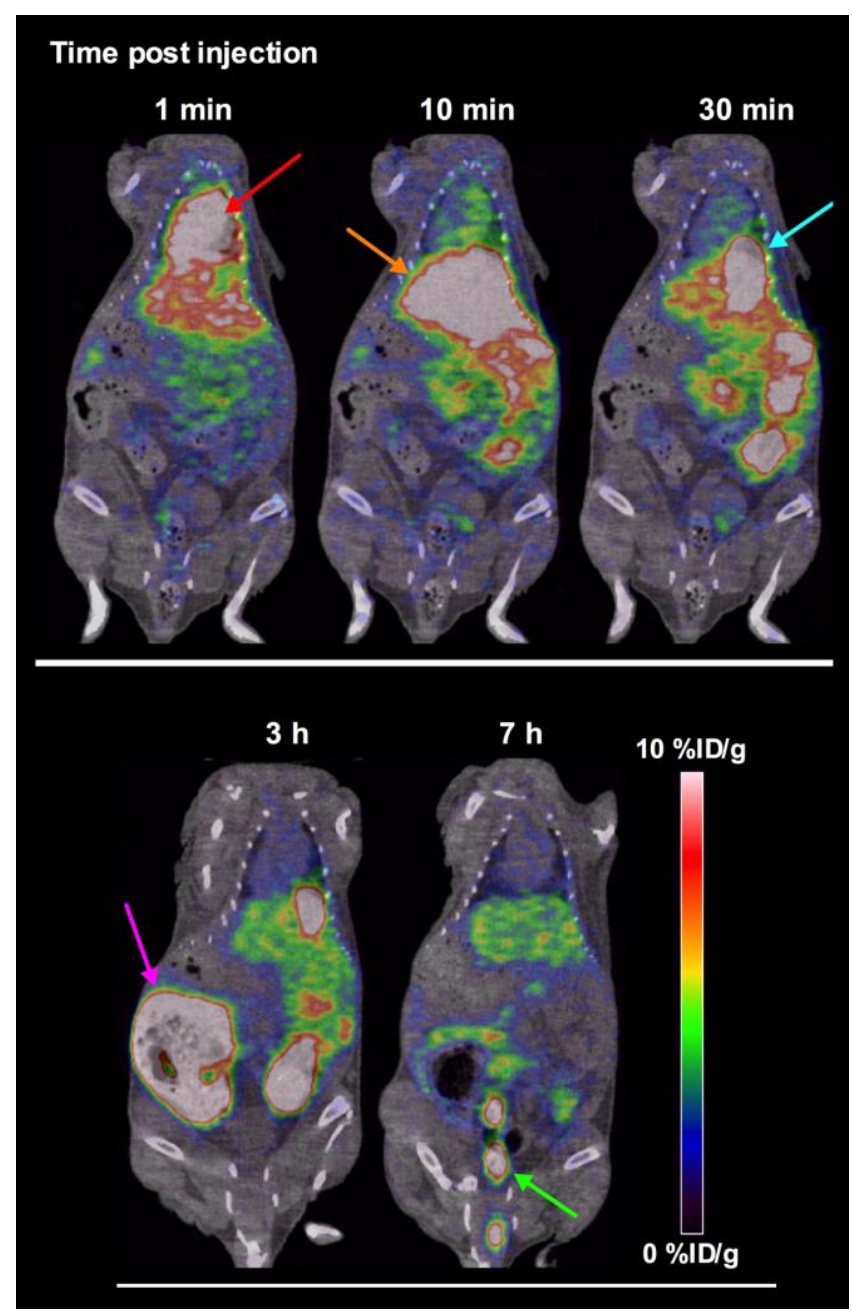

Figure 2, Representative PET/CT images following iv injection of $1.6 \mathrm{MBq}\left[{ }^{45} \mathrm{Ti}\right] \mathbf{2}$, ncaiv, at various time points after injection. The arrows point at the ROI corresponding to: red - heart/blood; orange - liver; blue - gall bladder; pink cecum; green: colon / feces.

After ncaiv PET the animals were sacrificed and ex vivo biodistribution studies were performed (Figure 3,bottom). Significant activity was found in the liver, and intestines, confirming the PET data, and also, in the lungs and the spleen. The tumor accumulation was $\sim 0.4 \% \mathrm{ID} / \mathrm{g}$. Next, we turned to the ncaip injections, followed by 3 and $7 \mathrm{~h} \mathrm{ex}$ vivo biodistribution studies (Figure 3, top, $\mathrm{n}=3$ ). Both time points showed similar distribution as the bulk of the complex accumulated in the liver, gall bladder and intestines. The highest tumor uptake was $0.5 \pm 0.03 \% \mathrm{ID} / \mathrm{g}$ at 3 hours. To some degree the route of administration did influence relative biodistribution: the ncaiv showed increased absorption of activity in lungs and blood, and reverse pancreas/spleen ratio compared to the ncaip formulation. The high value in the intestines at $3 \mathrm{~h}$ (ncaip) shows the accumulation in this organ before fecal excre- tion is responsible for the lower values observed at $7 \mathrm{~h}$. At $3 \mathrm{~h}$ post ncaip injection, blood, liver and gall bladder were each homogenized, mixed with ethanol and centrifuged. The supernatants were separated and the radioactivities measured at: gall bladder $88.3 \pm 1.4 \%$, liver $31.9 \pm 16.3 \%$, blood $13.7 \pm 3.3 \%$ (supernatant + pellets $=100 \%, \mathrm{n}=3$ ). The TLC/radio-TLC analyses performed on the supernatants of the liver and gall bladder (but not blood, due to low amount of radioactivity) showed that less than $1 \%$ of $\left[{ }^{45} \mathrm{Ti}\right]_{2}$ remained intact, while the rest of the radioactivity had no mobility on silica (compare to $\mathrm{R}_{\mathrm{f}}=0.57$ for $\left[{ }^{45} \mathrm{Ti}\right] \mathbf{2}$ ). Therefore, it appears that after 3 hours, most of the radioactivity in the blood has been metabolized and/or became associated with insoluble substances. No further attempts at structural identification of metabolites were made. Finally, to match the conditions of Immel et al., the ncaip formulation was extended with caip. The PET was generally consistent with ncaiv PET described above (see ESI). However, the $8 \mathrm{~h}$ ex vivo studies using combined caip and ncaip allowed the concentration of $\mathbf{2}$ to be calculated in the tumor volume, as shown in Table 1. In the case of ncaip, on average $113 \mu \mathrm{g}$ of 2 was injected, leading to a concentration of $257 \mathrm{pmol} / \mathrm{g}$. When no carrier was added, the percentage of injected dose was similar to the caip case (see ESI), suggesting that for the doses given, no saturation effects were observed in the clearance. 


\section{Ex vivo biodistribution ncaip}

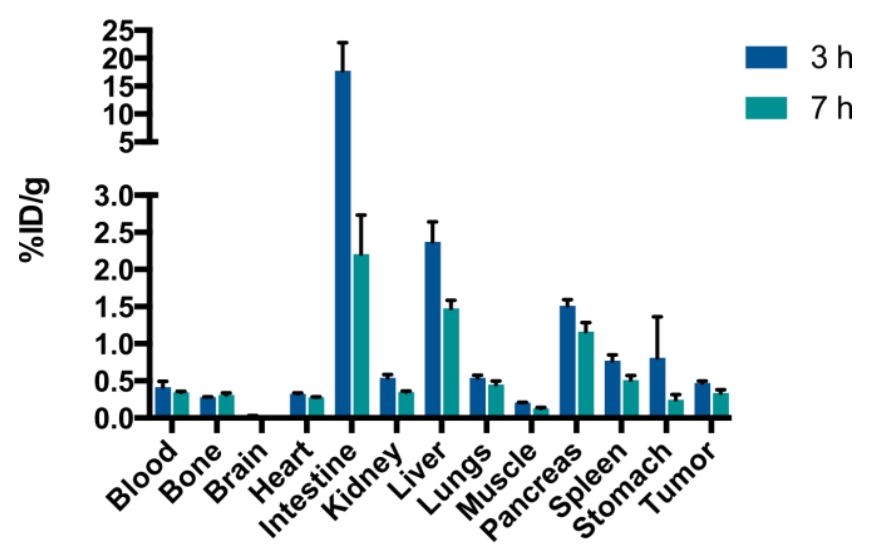

Ex vivo biodistribution ncaiv, $7 \mathrm{~h}$

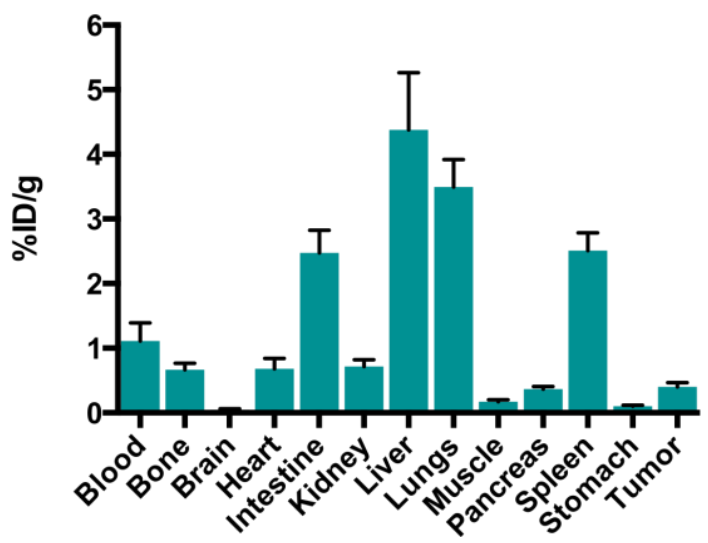

Figure 3, Ex vivo organ biodistribution data from ncaip (top) and ncaiv (bottom) injections, $\mathrm{n}=3$.

Due to the 3 hour half-life of ${ }^{45} \mathrm{Ti}$, and the low tumor accumulation, it was impossible to determine the long-term kinetics of the compound. It is reasonable that during the month-long treatment course used by Immel et al. that the doses were additive, leading to the observed antitumor effect.

The data above also suggest that chemical modifications to make the complex more hydrophilic, and thereby increase circulation time, or targeted drug delivery may improve the therapeutic value in vivo.

Table 1, Results of the $8 \mathrm{~h}$ ex-vivo biodistribution as pertain to the tumor tissue.

\begin{tabular}{llll}
\hline & $\begin{array}{l}\text { Injected } \mathbf{2} \\
(\boldsymbol{\mu g})\end{array}$ & $\begin{array}{l}\text { Tumor uptake } \\
(\mathbf{\%} \mathbf{I D} / \mathbf{g})\end{array}$ & $\begin{array}{l}\text { Tumor conc. } \\
(\mathbf{p m o l} / \mathbf{g})\end{array}$ \\
\hline ncaip & $1.2 \pm 0.1$ & $0.18 \pm 0.02$ & $3.8 \pm 0.5$ \\
caip & $113 \pm 6$ & $0.13 \pm 0.01$ & $257 \pm 24$ \\
\hline
\end{tabular}

- CONCLUSION
In conclusion, we reported an automated solid-phase radiosynthesis of $\left[{ }^{45} \mathrm{Ti}\right]_{2}$ and its PET and ex vivo evaluation in a HT-29 colorectal tumor bearing mice. $\left[{ }^{45} \mathrm{Ti}\right] \mathbf{2}$ was found to metabolize in the liver and to show fast hepatobiliary excretion pattern, with almost no renal clearance. We expect the synthetic methodology to be applicable to a broad range of supporting and terminal ligands. It is our hope that this advance will allow elucidation of the in vivo behavior of promising titanium compounds and become a useful tool for accelerating clinical translation. Ultimately, if found, a $\mathrm{Ti} /{ }^{45} \mathrm{Ti}$-based anticancer agent with fast and significant tumor uptake would combine chemotherapeutic effect with diagnostic and molecular imaging features, ushering the Ti-based metallodrugs into the growing field of theranostics.

\section{- EXPERIMENTAL SECTION}

${ }^{45} \mathrm{Ti}$ was produced by $10-20 \mu \mathrm{A}$ proton irradiation of $20-60$ mg scandium foil at approximately $13 \mathrm{MeV}$ by a GE PETtrace (after degradation from the nominal $16 \mathrm{MeV}$ extraction energy by $500 \mu \mathrm{m}$ thick aluminum). During irradiation the scandium was thermally stabilized by contact to a water-cooled silver plate. The ${ }^{45} \mathrm{Ti}$-loaded foils were dissolved in 2-4 $\mathrm{mL} 4 \mathrm{M} \mathrm{HCl}$, and the resulting solution was passed through a $0.45 \mu \mathrm{m}$ Whatman syringe filter, and dried under argon flow at $120-140{ }^{\circ} \mathrm{C}$. The residue was re-dissolved in $37 \% \mathrm{HCl}$ to a scandium concentration of roughly $20 \mathrm{mg} / \mathrm{mL}$, of which $1 \mathrm{~mL}$ was passed over $300 \mathrm{mg}$ Hypogel 2001,3 diol resin in an $8 \mathrm{~mm}$ ID column with polyethylene frits. The resin had been rinsed and preequilibrated with $37 \% \mathrm{HCl}$ for at least 20 min before application of the radioactive solution, and was kept wet with $\mathrm{HCl}$. Flow was slow and governed by gravity, where typically $1 \mathrm{~mL}$ passed through the column in 2-3 minutes. ${ }^{45} \mathrm{Ti}$ was retained on the column and scandium passed through. After washing with an additional 3-5 $\mathrm{mL}$ of $\mathrm{HCl}$, the column was dried by argon flow for 30 seconds.

(salan)Ti(dipic) was synthesized as described in the literature ${ }^{15}$ and its NMR properties $\left({ }^{1} \mathrm{H},{ }^{13} \mathrm{C}\right)$ were in full agreement with the reported data. Thin-layer chromatography (TLC) was run on pre-coated plates of silica gel 6o, F254 (Merck), eluent: ethylacetate-chloroform (1/1). Radio-TLC was performed with a Raytest MiniGita TLC scanner and Cyclone Plus Phosphor Imager(PerkinElmer).

Radiosynthesis was performed on a custom-made robotic synthesizer. The HypoGel 200 1,3-diol resin (30o mg) containing $1-4 \mathrm{GBq}$ of ${ }^{45} \mathrm{Ti}$ obtained in the previous step was washed with acetonitrile $(3.0 \mathrm{~mL}, 3.0 \mathrm{~mL} / \mathrm{min})$ to remove the residue of $\mathrm{HCl}$ from the column. A solution of salan in pyridine was then passed through the column (120 $\mathrm{mg}$ in $3.0 \mathrm{~mL}, 1.3 \mathrm{~mL} / \mathrm{min}$ ). The resin was then washed with pyridine $(5.0 \mathrm{~mL}, 3.0 \mathrm{~mL} / \mathrm{min})$ to remove residual salan, and a solution of dipic in pyridine $(35 \mathrm{mg}$ in $4.0 \mathrm{~mL}$ ) was recirculated through the column for 15 
min keeping the temperature of the recirculating solution at $100{ }^{\circ} \mathrm{C}$. Upon reaction with dipic $\left[{ }^{45} \mathrm{Ti}\right]_{2}$ entered the liquid phase. The resulting solution containing a mixture of $\left[{ }^{45} \mathrm{Ti}\right]_{2}$ and dipic in pyridine was passed through a SepPak Silica Plus cartridge and into $5 \%(\mathrm{w} / \mathrm{v})$ aqueous ammonium chloride $(45 \mathrm{~mL})$. The resulting aqueous mixture was passed through a Sep-Pak C18 Plus cartridge, and the cartridge was washed with water (10 mL). The product was then eluted in ethanol $(3.0 \mathrm{~mL})$, yielding $\left[{ }^{45} \mathrm{Ti}\right] 2$. After removal of samples for quality control experiments, the ethanol solution containing $\left.{ }^{45} \mathrm{Ti}\right]_{2}$ was taken to dryness with helium flow at $60^{\circ} \mathrm{C}$ in preparation for in vivo formulation.

In the first experiment, three mice received $150 \mu \mathrm{L}$ injections of ncaiv via the lateral tail vein $(1.6 \pm 0.18 \mathrm{MBq})$. After intravenous administration of ncaiv, PET acquisitions were performed for the first 30 minutes (dynamic acquisition) and then $2 \times 12$ minutes at 3 and 7 hours after injection. All PET acquisitions were followed by $\mathrm{CT}$ imaging. In the second experiments, six mice received $50 \mu \mathrm{L}$ ncaip $(1.2 \pm 0.1 \mathrm{MBq})$. In the final experiment, four mice received $50 \mu \mathrm{L}$ intraperitoneal injections of ncaip (14.4 $\pm 0.9 \mathrm{MBq})$ and another four mice received $50 \mu \mathrm{L}$ intraperitoneal injections of caip (13.0 $\pm 0.7 \mathrm{MBq})$. For the intraperitoneal injections in the last experiment, PET acquisitions were performed for 3, 6 and 10 minutes at 1,3 and 7 hours (respectively) after administration of ncaip or caip $\left[{ }^{45} \mathrm{Ti}\right]$ 2. Ex vivo biodistribution was performed 3 and 7 hours after injection of ncaip $\left[{ }^{45} \mathrm{Ti}\right]_{\mathbf{2}}$ in the second experiment and $8 \mathrm{~h}$ after injection in the last experiment.

Region of interest (ROI) analysis was applied on the dynamic PET data to estimate the blood clearance of $\left[{ }^{45} \mathrm{Ti}\right]_{2}$ injected intravenously (ncaiv). ROIs were drawn over the heart to estimate the activity in the blood pool. The time activity curve was fitted with a single exponential function to estimate the blood clearance halftime (Graphpad Prism 6.o).

Animals were sacrificed after the last imaging time-point and their organs excised, weighed, and counted in a gamma well counter (Wizard2, PerkinElmer) for conventional ex-vivo biodistribution.

\section{- ASSOCIATED CONTENT}

${ }^{*} S$ Supporting Information contains general information, Ti/Sc distribution constants, description of automation, quality control, formulation, animals and cell lines description. This material is available free of charge via the Internet at http://pubs.acs.org.

\section{- AUTHOR INFORMATION}

Corresponding Authors

*For F.Z.: phone, +45 4677 53 37; E-mail, fezh@dtu.dk Notes

The authors declare no competing financial interest.

\section{- ABBREVIATIONS USED}

salan, 6,6'-((ethane-1,2-diylbis (methylazanediyl)) bis(methylene)) bis(2,4- dimethylphenol); dipic, pyridine2,6-dicarboxylic acid; ICP-OES, inductively coupled plasma atomic emission spectroscopy; HT29, human colorectal adenocarcinoma; OVCAR-1, human ovarian epithelial carcinoma; HeLa, human cervical adenocarcinoma; Hep G2, hepatocyte carcinoma; SPE, solid phase extraction; ROI, region of interest; caip, carrier-added intraperitoneal; ncaip, non-carrier-added intraperitoneal; CT, computed tomography; \%ID percent injected dose.

\section{- REFERENCES}

(1) Tan, C.-P.; Lu, Y.-Y.; Ji, L.-N.; Mao, Z.-W. Metallomics 2014, 6 (5), 978-995.

(2) Mjos, K. D.; Orvig, C. Chem. Rev. 2014, 114 (8), 45404563.

(3) Gaynor, D.; Griffith, D. M. DALTON Trans. 2012, 41 (43), 13239-13257.

(4) Caruso, F.; Rossi, M. MINI-Rev. Med. Chem. 2oo4, 4 (1), 49-6o.

(5) Buettner, K. M.; Valentine, A. M. Chemical Reviews. 2012, pp 1863-1881.

(6) Tshuva, E. Y.; Ashenhurst, J. A. Eur. J. Inorg. Chem. 2009, 2009 (15), 2203-2218.

(7) Glasner, H.; Tshuva, E. Y. Inorg. Chem. 2014, 53 (6), 3170-3176.

(8) Tshuva, E. Y.; Peri, D. Coord. Chem. Rev. 20o9, 253 (1516), 2098-2115.

(9) Shavit, M.; Peri, D.; Manna, C. M.; Alexander, J. S.; Tshuva, E. Y. J. Am. Chem. Soc. 2007, 129 (40), 1209812099.

(10) Peri, D.; Meker, S.; Shavit, M.; Tshuva, E. Y. Chem. - Eur. J. 2009, 15 (10), 2403-2415.

(11) Manna, C. M.; Tshuva, E. Y. DALTON Trans. 2010, 39 (5), 1182-1184.

(12) Manna, C. M.; Armony, G.; Tshuva, E. Y. Inorg. Chem. 2011, 50 (20), 10284-10291.

(13) Meker, S.; Manna, C. M.; Peri, D.; Tshuva, E. Y. DALTON Trans. 2011, 40 (38), 9802-9809.

(14) Tshuva, E. Y.; Peri, D. Coord. Chem. Rev. 2oog, 253 (1516), 2098-2115.

(15) Immel, T. A.; Grützke, M.; Späte, A.-K.; Groth, U.; Öhlschläger, P.; Huhn, T. Chem. Commun. Camb. Engl. 2012, 48 (46), 5790-5792.

(16) Matthews, P. M.; Rabiner, E. a.; Passchier, J.; Gunn, R. N. Br. J. Clin. Pharmacol. 2012, 73, 175-186.

(17) Zeevaart, J. R.; Wagener, J.; Marjanovic-Painter, B.; Sathekge, M.; Soni, N.; Zinn, C.; Perkins, G.; Smithd, S. V. J. Label. Compd. Radiopharm. 2013, 56 (April), 495503.

(18) Burrows, T. W. Nucl. Data Sheets 2008, 109 (1), 171-296.

(19) Thomas, R. G.; Bartolini, W. Nucl. Phys. A 1968, 106 (2), 323-336.

(20) Collins, J. M.; Uppal, R.; Incarvito, C. D.; Valentine, A. M. Inorg. Chem. 2005, 44 (10), 3431-3440.

(21) Ishiwata, K.; Ido, T.; Monma, M.; Murakami, M.; Fukuda, H.; Kameyama, M.; Yamada, K.; Endo, S.; Yoshioka, S.; Sato, T.; Matsuzawa, T. Int. J. Rad. Appl. Instrum. [A] 1991, 42 (8), 707-712. 
(22) Vavere, A. L.; Laforest, R.; Welch, M. J. Nucl. Med. Biol. 2005, 32, 117-122.

(23) Vavere, A. L.; Welch, M. J. J. Nucl. Med. Off. Publ. Soc. Nucl. Med. 2005, 46 (4), 683-69o.

(24) Baillon, F.; Provost, E.; Fürst, W. J. Mol. Liq. 2008, 143 (1), 8-12. 